on the lateral incisor causing pain, that tooth was extracted; after which the intolerance of light, previously most distressing, and 'a disagreeable gnawing or pinching sensation at the back of the eye' ceased. An abscess was found at the point of the fang. In another case, a gentleman who had suffered two years previously from a slight attack of iritis; upon recovery experienced, when he attempted to read, a peculiar uneasiness in his eyes. After the extraction of a tooth, at the root of which an abscess was found, he was entirely relieved. In a third case, a young lady subject to frequent severe attacks of inflammation in the eyes, with excessive intolerance of light, was greatly relieved by the extraction of some decayed teeth.

I here bring to a conclusion these inquiries respecting the inflammations of the eyeball. They embrace some of the most important diseases of this organ, and bring together facts and results calculated to instruct by comparison. I am convinced that the subject is one not only of importance as regards the inestimable value of sight, but as affording most valuable illustrations of disease in general."

Charles Lever, who studied medicine in Dublin, has immortalized one of the prominent Irish medical men in the "Confessions of Harry Lorrequer," namely, Cusack Roney; one would have thought that the polemical Jacob would have offered equal facilities for reproduction in one of Lever's novels, but I am not aware that such is the case.

I am indebted to Miss Euphan Maxwell for obtaining the photograph from the Registrar of the Royal College of Surgeons in Ireland, and to the latter for permission to reproduce it.

\title{
ON THE MOVEMENT OF THE INTRAOCULAR FLUID AS TAUGHT BY THEODOR LEBER
}

\author{
BY \\ Priestley Smith, Sen. \\ BIRMINGHAM
}

MANY ophthalmic surgeons must, I think, have been perplexed or even seriously disturbed by the vigorous attack on Leber's teaching made of late years by certain well-known physiologists in Germany and France. Others will probably now be so by the revival of it in Duke-Elder's important monograph "The Nature of the Intraocular Fluids." To abandon one's old belief in a slow continuous movement of fluid from the ciliary processes, forward 
through the pupil, and outward at the angle of the anterior chamber, woula be to lose a rational explanation of morbid conditions that are met with every day. If the belief is wrong of course it must go at any cost, and much of our modern ophthalmology must be rewritten, but I think the dissentients have not proved their case.

Leber held that the ciliary processes emitted fluid because the pressure of the blood in their capillaries was higher than that of the fluid in the chambers, and that Schlemm's canal and the associated veins absorbed it because the blood-pressure in these vessels was lower than the chamber-pressure, in short, that the fluid was slowly renewed by simple filtration due to hydrostatic pressure. He supposed that Schlemm's canal was safeguarded against collapse by its position in the sclera. This view was generally accepted and held for many years without demur, but when the iris veins were shown to take part in the removal of the fluid a difficulty arose of which Leber himself was well aware. In 1906 he wrote: "Whether and how these veins can possibly have a blood-pressure lower than the chamber-pressure, and yet not suffer compression of their lumen, needs further explanation." (1) So far as I know he did not himself answer the question : he did not recognize that the iris veins might take up fluid from the chamber even though their blood-pressure was higher than the chamber-pressure-which it certainly is.

The answer lay in the osmotic pressure of the blood. Ten years earlier (1896) Starling ${ }^{(2)}$ had shown : (1) that a one per cent. salt solution injected into the limb of an animal so as to cause oedema is freely absorbed by blood plasma moving through the vessels of the limb; (2) that when the solution and the plasma are separated by a thin animal membrane outside the body, the plasma absorbs the fluid until a pressure-difference of $25-30 \mathrm{~mm}$. $\mathrm{Hg}$ is reached; and (3) that when a greater difference is artificially established, fluid passes through the membrane in the opposite direction. It was long, however, before these important findings were applied to the physiology of the aqueous. Only a few of the many notable workers on this subject can be mentioned here.

Since 1904 Otto Weiss ${ }^{(3)}$ has maintained that Leber's teaching was at fault in its disregard of osmotic pressure-and in other ways. Hertel (1914), ${ }^{(4)}$ by injecting various solutions into the blood-stream, showed that the production and absorption of the aqueous, as manifested in the tension of the eye, could be greatly influenced by altering the composition of the blood. Seidel,(5) an ardent supporter of Leber and a highly skilled experimenter, has admitted (1919) that osmotic pressure plays a part in the renewal of the aqueous. Lehmann and Meesmann (1924), ${ }^{(6)}$ studying the osmotic changes that occur between blood and aqueous in normal 
and abnormal conditions, found a redistribution of constituents agreeing with the osmotic principle, and therewith explained a fact inexplicable by the filtration theory, viz., that the aqueous contains a higher percentage of chloride than does the blood. Duke-Elder, ${ }^{(i)}$ as readers of this journal know, has still more recently (1926-27) reinvestigated by extremely delicate methods both the osmotic changes and the blood-pressures in the eye. Reference to a host of other workers on the subject is given in his articles.

No one, I suppose, now doubts that Leber's teaching as to the nature of the renewal process was defective in so far as it took no account of the absorbent power of the blood, but certain physiologists have gone much further than this in the way of dissent.

Professor C. Hamburger concluded from various experiments of his own that there was no forward movement of fluid through the pupil; that a "physiological barrier" against such movement existed at the pupil; that the fluid in the posterior aqueous chamber differed widely from that in the anterior; and that the fluid in the anterior chamber came from the iris, not from the processes.

Professor $\mathrm{O}$. Weiss ${ }^{(8)}$ in a recent article has restated the objections that he and others have brought against Leber's teaching in detail, and has declared it as a whole to be unproved and obsolete. In particular he holds that movement of the fluid through the pupil is not proved; that its production by one group of vessels and absorption by another is not proved; and that its renewal, in so far as this occurs at all, is effected by dialysis throughout the whole of the intraocular vascular system.

Duke-Elder ${ }^{(9)}$ deals with the subject comprehensively and is largely in agreement with Weiss. He holds that the prevailing view as to the formation and circulation of the aqueous is wrong; that the fluid is neither a secretion nor, in the accepted sense, a transudate from the blood; that it is a dialysate; that it does not circulate actively through the eye, being in osmotic equilibrium with the capillary blood, but that it is subject nevertheless to a minimal and intermittent circulation induced by muscular movements. His position is not quite definite for towards the end of the work (p. 108) he writes : "It would seem, however, that the existence of a circulation, as elaborated by Leber, cannot altogether be denied," while on the following page one reads: "On either side of the capillary walls there is a balancing hydrostatic and osmotic pressure-equilibrium," a condition which, as he says elsewhere (p. 72), must render the fluid "essentially stagnant."

The question of chief interest to the clinical worker is whether the fluid does or does not move slowly and steadily along the path 
described by Leber, and I think it may be raised even by an ex-clinician who knows nothing of modern bio-chemistry. Questions of chemical affinity, molecular concentration, and electric currents are not in dispute here; I do not presume to doubt the findings of experts in these subjects-though I notice that they do not always quite agree. My point is that the alleged stagnation of the intraocular fluid is not proved by the facts put forward, and is contradicted by a mass of valid evidence. If in the wrong, I hope at least to elicit some further explanation.

Two forces have to be considered : the osmotic, which alters the constitution of the fluids in subtle ways and tends to cause movement in bulk from the chambers, through the wall of the vessel, into the blood-stream; and the hydrostatic, which tends to cause movement in bulk in the opposite direction. When these forces are exactly balanced there is no transit of fluid in either direction, but there is a difference of hydrostatic pressure on the two sides of the membrane representing exactly the difference of osmotic force in the two fluids. The fluids are then in osmotic equilibrium.

The dissentients hold that the aqueous and the capillary blood are in osmotic equilibrium, with slight alternating variations from it in both directions (Duke-Elder), and their argument, if I understand it, is this. Minute examination of the chemical conditions of the fluids indicates such equilibrium; the difference between their hydrostatic pressures, though not exactly measurable, lies within limits that are compatible with such equilibrium; therefore the equilibrium exists. The conclusion seems hardly safe.

By wonderfully delicate methods Duke-Elder has made fresh measurements of the blood-pressure in certain arteries and veins within the eye, but like Henderson and Starling when they dealt with the question twenty years ago, he can only state the capillary pressure as lying within certain limits. He assumes it to be just high enough to establish osmotic equilibrium, which implies stagnation of the fluid in the chambers. But if we choose to assume it to be slightly above the equilibrium point in one region of the eye, and slightly below it in another, we at once account for the slow steady movement of the fluid through the chambers which Leber described and most of us believe in.

Is there any sufficient reason against this alternative assumption? Certain facts seem to drive one to it. The blood-pressure is higher in the ciliary capillaries than in Schlemm's canal and the iris-veins, while the aqueous pressure hardly differs in the two regions; it is difficult therefore to see how osmotic equilibrium can exist in the two regions at the same time. The departure from equilibrium in the two directions may be very small, for the movement of the fluid-as we believe it to occur-is very slow. 
To speak of the movement as a stream through the chambers is to create a false impression. Take the escape from the chamber to be $5 \mathrm{cmm}$. per minuteLeber's original estimate-and to be equally distributed around the circumference ; take the circumference to be $35 \mathrm{~mm}$., and the depth of the visible chamber at its margin $1 \mathrm{~mm}$.; then the rate of movement outward at the margin will be one-seventh of a millimetre per minute, or one four hundred and twentieth per second-a movement much slower than that of the long hand of an ordinary watch. Assuming the surface of the iris to remove some of the fluid the movement will be slower still. It will certainly not be discoverable even with the slit-lamp on watching the movement of particles suspended in the aqueous; it will be completely masked by the much more rapid movement due to thermal currents.

Another suggestive fact-which I learn from Duke-Elder's work - may be noted here : blood in the venous state has a considerably higher osmotic pressure than in the arterial state.

Those who deny that the fluid moves continually in a certain direction rely at present, if I am not mistaken, chiefly on the supposed osmotic equilibrium of the blood and the aqueous, but other arguments are still put forward. Let us glance at these and then turn to the evidence in favour of the movement.

Hamburger's various objections have been met one after the other by Seidel, ${ }^{(10)}$ who has shown, conclusively as it seems to me, that they rested largely on inadequate experiments.

To test the alleged difference between the fluid in the posterior aqueous chamber and that in the anterior, Seidel first determined the relation of refractive index to albumen percentage in many specimens of normal and abnormal aqueous. Then, with the refractometer, he compared small samples taken with all possible avoidance of disturbance from the two chambers of the same eye, in cats and rabbits in slight ether-narcosis. The fluid was identical in the two chambers and when vitiated by increase of albumen after vascular disturbance of various degrees it was pqually vitiated in both.

To study the supposed retention behind the iris of coloured fluid injected in small quantity into the posterior aqueous chamber, he watched for the appearance of the colour in the pupil with the slit-lamp. It appeared in one to five minutes, whereas under the weaker illumination used by Hamburger it did not appear until much later. No "physiological barrier" was discovered.

To observe the advent of colour in the ciliary processes and iris of rabbits after systemic injection of coloured fluids, Seidel used albinos instead of pigmented subjects, and moderate doses of isotonic solutions instead of larger and more concentrated doses. The processes (which are attached to the back of the iris in the rabbit, and are seen through it in the albino) displayed its presence sooner than did the iris proper. They were not "refractory" to its reception, but the reverse.

Seidel's ${ }^{(11)}$ observations as to the relative activity of the irisveins and Schlemm's canal in the absorption of the aqueous are important. They seem to prove that whereas the blood-pressure in the iris is a little higher than the chamber-pressure, that in the episcleral veins is a little lower, and accordingly that fluid passes from the chamber more freely into the canal than into the iris.

In living rabbits a fine syringe half filled with coloured solution was introduced into the anterior chamber while the pressure in the latter was controlled with a Schiötz tonometer. A small quantity of normal aqueous was drawn into the syringe and immediately became mixed with the colour solution; without disturbance of the needle it was then returned to the chamber in sufficient quantity to restore the previously ascertained chamber-pressure. The episcleral veins were watched for change of colour. Under normal chamber-pressure, and even under slightly subnormal they showed the alien colour; when the chamber-pressure was considerably sub-normal they recovered their blood colour. 
I now turn to evidence that points more directly to a continuous forward movement of the fluid.

The well-known experiments of Nuel and Benoit $t^{(12)}$ on two healthy human eyes doomed to excision by reason of orbital growths gave striking evidence of a current-under artificial conditions. Chinese ink was used because insoluble particles in suspension are better for the purpose than coloured solutions; they do not travel by diffusion but move with the fluid until they are filtered out of it by the membranes through which the fluid passes; the microscope shows where this happens.

A drop of filtered Chinese ink was injected into the vitreous two and a half hours before excision in one case, five hours in the other. After excision the natural pigment was bleached so that it could not be mistaken for ink particles. The larger particles were held back by the hyaloid, the smaller passed through it into the posterior chamber. Here they found no entrance into the free surface of the ciliary body or into the posterior surface of the iris. Passing through the pupil into the anterior chamber the particles entered the anterior surface of the iris freely through large crypts at its base and near to the pupillary edge, massing themselves around the iris-veins. They were massed also in the angle of the chamber, outside Schlemm's canal on the side nearest to the chamber, and around the veins that pass through the ciliary muscle and the larger veins connecting the iris and processes with the vortex veins (see the illustration in the criginal paper, or in Parsons' Pathology, p. 992).(13)

It may be reasonably objected that the current thus demonstrated was not pre-existent but merely generated by the injection. The authors say that the amount injected was "hardly a drop" and that it caused "no sensible hardening of the eye." Gifford (1886)(14) in similar experiments on animal eyes allowed some vitreous fluid to escape through a puncture before injecting the ink, and still found evidence of the forward current. This does not completely answer the objection, for the intraocular pressure was certainly disturbed, but at least the experiments clearly showed the paths along which the fluid escapes most easily from the eye.

No such objection can be raised to Ulbrich's ${ }^{(15)}$ well-known observations on an intact living human eye.

The iris presented, in addition to a free pupil, a small congenital aperture, closed by a thin flaccid membrane. When the eye and lids were at rest the membrane bulged forward like a tiny blister. Forcible closure of the lids drove it back making it markedly concave. Accommodation did the same. In each case it recovered its previous position regularly in about thirty seconds, and in the case of accommodation this took place though the accommodative effort persisted. Pressure on the cornea drove it back in like manner, but recovery was instantaneous when the pressure ceased. Alteration of the pupil under influence of light, and dilatation by euphthalmine, did not interfere with the phenomenon.

If we imagine the fluid to move slowly forward and to meet with a slight resistance in passing between the iris and the lens, the explanation of this case is simple. Because of that resistance the pressure is slightly greater in the posterior chamber than in the anterior, and the membrane consequently bulges forward so long as the pressures are not disturbed. Strong closure of the lids reverses the pressures by suddenly pressing on the globe and 
forcing a little extra fluid through the pupil into the anterior chamber, and so renders the membrane concave. The normal current restores it to its usual position in a definite time. Accommodative effort carries the pupillary zone of the iris forward on the surface of the lens while the peripheral zone is pushed backwards by the displaced aqueous (Helmholtz). Therewith the membrane becomes concave, but recovers its position as before in spite of continued accommodation. After pressure on the cornea recovery is instantaneous because no fluid has been driven through the pupil. It is difficult to see what other explanation could be given.

Again certain morbid conditions of the eye bear witness to the continuous movement of the fluid, or to obstruction of its movement. Outline sketches of a few typical examples will be enough to show their significance.

A small melanosarcoma of the iris, of some years standing, demands excision of the eye. Cells cast off by the tumour are shown by the microscope to be lodged in the tissues around the angle of the chamber throughout its whole circle-like the ink-particles in the injection-experiments, but not carried thither by an artificial current of fluid.

Through chronic mild iritis the pupil margin becomes adherent throughout its whole circle to the lens capsule. The rest of the iris bulges forwards, being displaced by fluid collected behind it; a secondary glaucoma ensues. A timely iridectomy restores a channel from the posterior to the anterior chamber; the bulge subsides at once; the tension falls; the eye is saved.

$\Lambda$ lens imperfectly attached from birth becomes completely detached many years later. One day, while the head is bent over the washing-basin, the lens passes into the anterior chamber. Pain and high tension quickly follow and advice is sought. The whole pupil is seen through the lens; the peripheral zone of the iris is in contact with the cornea, being driven forward around the lens margin by pressure of fluid imprisoned behind it. Before operation can be undertaken the lens passes back through the pupil; pain and tension quickly subside. The same displacement recurs several times, each time with a secondary glaucoma, and spontaneous recovery. At last, with special precautions against falling backwards of the lens at the moment of operation, the lens is removed and no further glaucomatous attacks occur. (I6)

As in the previous case, a detached lens passes into the anterior chamber but does not occlude the pupil completely; a free space remains between its upper edge and the pupil margin. The peripheral zone of the iris is not pushed forward; there is little discomfort and no injection. There is no secondary glaucoma. In a case similar to the foregoing, there is no rise of tension until, in preparing for operation, eserine is used to prevent the lens from falling back through the pupil. Then, the pupil being contracted and completely behind the lens, secondary glaucoma supervenes.(17) A lens which is rough, shrivelled, and chalky-looking as the result of injury received years previously, falls into the anterior chamber. It is too small to occlude the pupil. Some pain follow's the dislocation for a few days, but soon subsides. Eighteen months after the dislocation tension is still normal. There has been no secondary glaucoma. 'The lens is extracted with good result.

Inference.-Secondary glaucoma after dislocation of lens into anterior chamber is due to obstruction in path of fluid, not to inflammation.

The evidence pointing to production of the fluid by the ciliary processes is of various kinds and too well known to need detailed description. First, we have their structure, and their position in relation to the chambers; secondly, the comparative ease with which diffusible colouring matter in the blood passes from their capillaries into the chambers; thirdly, the lack of fluid that results from their 
experimental removal (Deutschmann), or from the cutting off of their special blood supply (Wagenmann) and the comparative non-effect of removal or absence of the iris, and of arrested blood supply to the choroid, or retina, or both; and lastly, the effects on the production of the fluid produeed by cyclitis on the one hand, and by choroiditis, retinitis, or iritis on the other.

To show that the angle of the chamber provides for continuous removal, and that obstruction here overfills the eye with fluid, one might, if necessary, cite various types of glaucoma. It is true that the most conspicuous type of all, acute primary glaucoma, still awaits full explanation of one feature-the advance of the lens at the time of the attack-but it is impossible I think, for the high chamber-pressure of acute glaucoma to occur otherwise than by hindrance at the main outlet.

To this substantial mass of evidence, most of which is far from new, no satisfactory answer has been given. In his recent review of the matter Weiss ${ }^{(8)}$ does not meet even that which comes from the physiological laboratory. He recalls the objections raised by Hamburger but gives no account of their refutation by Seidel. The clinical evidence fares little better. We are told that the Ulbrich case can be explained without recourse to continuous movement of the fluid, but not exactly how. The iris bombé argument is met by saying that total adhesion of the iris to the lens is not always followed by secondary glaucoma-which of course is true, for it is often associated with destructive iridocyclitis-but no explanation is given of the secondary glaucoma that does occur, or of its subsidence when an aperture is made in the iris.

It seems to me that the dissentients, relying on the findings of physico-chemistry, attach too little weight to clinical observation : that their attitude for the most part is too exclusive. Thus Weiss attributes the renewal process wholly to molecular force, and looks to the bio-chemistry of the future to explain what cannot yet be explained on that basis; he neither admits nor denies a continuous movement of the fluid. Magitot ${ }^{(18)}$ entirely denies the existence of such movement. Duke-Elder begins his valuable treatise with a strongly subversive argument, but later makes considerable concession to old beliefs.

Subject to correction, I submit that we are fully justified in maintaining that under the influence of two opposing forces the fluid moves slowly and continuously through the chambers : that the ciliary capillaries emit the fluid because their blood-pressure is high enough to overcome the osmotic force, while Schlemm's canal and the iris veins absorb it because here the blood-pressure is lower and the osmotic force prevails. 
Leber's teaching as to the nature of the renewal process was weak at one point no doubt-it paid no heed to the absorbent power of the blood; but as to the source, the path, and the exit of the fluid it stands, I think, unshaken and invaluable.

\title{
REFERENCES
}

1. Leber und Pilzecker.-Neue Untersuchungen, etc. New researches on the fluid interchange in the eye. Arch.f. Ophthal.. Bd. LXIV, 1906.

2. Starling.-Jl. of Physiol., Vol. XIX, 1896.

3. Weiss, O.-Die Ernährung, etc. The nutrition and circulation of the eye. Nagel's Handbuch der Physiol., 1904.

4. Hertel. - The dependence of the intraocular pressure on the composition of the Blood. Arch.f. Ophthal., Bd. LXXXVIII, H. 2, S. 197, 1914.

5. Seidel.-Arch.f. Ophthal., Bd. CI, S. 403 (foot-note), 1919.

6. Lehmann and Meesmann.-Pflüger's Arch. f. Physiol., Bd. CCV, S. 210, 1924.

7. Duke-Elder. - Intraocular and osmotic pressure. Ocular circulation. Brit. Jl. of Ophthal., Vol. X, pp. 1 and 513, 1926.

8. Weiss, O.-Herkunft, und Schicksal, etc. Source and destination of the intraocular fluids. Deutsch. med. Wochenschr., SS. 21 and 63, Jan., 1925.

9. Duke-Elder. - The nature of the intraocular fluids. Monograph Supplement to Brit. Jl. of Ophthal., 1927.

10 Seidel.-Experimentelle Untersuchungen, etc. Experiments on the source and movement of the intraocular fluid. A series of articles in Arch. $f$. Ophthal., 1918-1921.

11. Idem-Bd. CIV, H. 3, S. 357.

12. Nuel and Benoit.-Arch. d'Ophtal., T. XX, 1899.

13. Parsons.-Pathology of the Eye, p. 992.

14. Gifford.-The direction of the lymph-streams in the eye. Arch. of Ophthal., p. 153, 1886, and Ophthal. Rev., p. 270, 1886.

15. Ulbrich.-Rep. of Ophthal. Soc. Heidelberg., Meeting of 1907, p. 105.

16 Priestley Smith.-Glaucoma, its causes, etc. London : Churchill, 1879. Cases of dislocation of lens into anterior chamber, p. 183 and pp. 262-5.

17. Minor, J. J. - New York Med. Jl., p. 194, 1881.

18. Magitot.-Ann. d'Ocul., Vol. CLIV, 1917.

\section{VISUAL FIELD CHANGES IN PREGNANCY}

BY

\author{
H. M. Traquair \\ EDINBURGH
}

THOSE who have been sceptical as to the production of bitemporal hemianopia by pressure on the chiasma by the physiologically enlarged pituitary body in pregnancy will welcome Dr. Abramowicz's paper in the January issue of the BrITISH Journal of Ophthalmology. In 81 pregnant women Dr. Abramowicz found only five who showed "slight temporal contractions of the visual fields" and this feature he cautiously-and wisely-considers "may be occasioned by the hypertrophy of the pituitary body" 